\title{
Optimasi Jaringan Internet Di Gedung Teknik Elektro Politeknik Negeri Sriwijaya
}

\author{
Suci Tri Lestari' ${ }^{1}$, Suroso $^{2}$, Ibnu Ziad ${ }^{3}$ \\ 1,2,3 Politeknik Negeri Sriwijaya \\ Jl .Srijaya Negara Bukit Besar, Palembang \\ ${ }^{1}$ sucitrilestari78@yahoo.com, 20sorus11@gmail.com,3 ibnupoltek1@gmail.com
}

\begin{abstract}
Nowadays wireless communication has become a basic necessity for the community. WiFi (wireless fidelity) One of them, which is a local network that uses an electromagnetic signal that works at a frequency of $2.4 \mathrm{GHz}$. Tool to implement WiFi is Access point (AP). The toughest bully in the world of WiFi is known for interference. Interference is the use of the same frequency or channel on a network. Interference can cause service quality to decline so that it is less optimal in its usage, therefore the optimization needs to the network so that users can use the network without constraints. From the results of the research that has been done, the optimization is done by evaluating the selection of the channel from each access point studied with the access point that was concluded that the optimization of the results of all access points experienced Improved signal quality as in AP 1 prior to optimized (-64.0) $\mathrm{dBm}$ to (-56.0) $\mathrm{dBm}$ category good and after optimized (-56.0) $\mathrm{dBm}$ to (-48) $\mathrm{dBm}$ category excellent.
\end{abstract}

Keywords: Optimization, Wireless, interference, QoS (Quality of Service)

\section{Abstrak}

Saat ini komunikasi tanpa kabel/nirkabel (wireless) telah menjadi kebutuhan dasar bagi masyarakat. Wifi (wireless fidelity) salah satunya, yang merupakan jaringan lokal yang menggunakan sinyal elektromagnetik yang bekerja pada frekuensi 2,4 GHz. Alat untuk mengimplementasi wifi yaitu access point (AP). Pengganggu terberat dalam dunia wifi dikenal dengan interferensi. Interferensi merupakan penggunaan frekuensi atau channel yang sama pada suatu jaringan. Interferensi dapat menyebabkan kualitas layanan menurun sehingga kurang optimal dalam pemakaiannya, maka dari itu diperlukannya optimasi terhadap jaringan agar para pengguna (user) dapat menggunakan jaringan tanpa kendala. Dari hasil penelitian yang telah dilakukan, optimasi dilakukan dengan mengevaluasi pemilihan channel dari setiap access point yang diteliti dengan access point yang disekitar didapat kesimpulan bahwa dari hasil optimasi tersebut semua access point mengalami peningkatan kualitas sinyal seperti pada AP 1 sebelum dioptimasi $(-64,0) \mathrm{dBm}$ to $(-56,0)$ $\mathrm{dBm}$ berkategori good dan setelah dioptimasi $(-56,0) \mathrm{dBm}$ to $(-48) \mathrm{dBm}$ berkategori excellent.

Kata kunci: Optimasi, Wireless, Interferensi, QoS (Quality of Service)

\section{PENDAHULUAN}

Saat ini perkembangan teknologi informasi dan komunikasi berkembang sangat pesat. Salah satunya teknologi yang paling diminati oleh masyarakat saat ini yaitu wifi (wireless fidelity). Teknologi wifi sangat dibutuhkan bagi masyarakat terutama pada lingkungan perkuliahan untuk mengakses internet. Banyaknya 
pengguna internet memungkinkan kualitas layanan sering terjadi penurunan performansi jaringan. Dalam kurun waktu beberapa bulan terakhir kinerja jaringan wifi yang ada pada gedung Teknik Elektro Politeknik Negeri Sriwijaya mengalami penurunan performansi yang dikenal dengan interferensi. Interferensi merupakan sinyal yang berkompetisi dalam band frekuensi sama yang saling tumpang tindih sehingga dapat mengubah atau menghapus sinyal. Jika terjadi interferensi maka mengakibatkan penurunan QoS (Quality of Service) yang menyebabkan sinyal wireless tidak maksimal dan kurang optimal dalam pertukaran data pada jaringan wireless tersebut[1]. Berdasarkan uraian diatas maka diperlukannya optimasi layanan jaringan internet sehingga para pengguna (user) dapat menggunakan internet dengan maksimal.

\section{METODOLOGI PENELITIAN}

Metode penelitian yang digunakan pada penelitian ini adalah metode action research atau penelitian tindakan. Adapun tahapan penelitian action research ini yaitu :

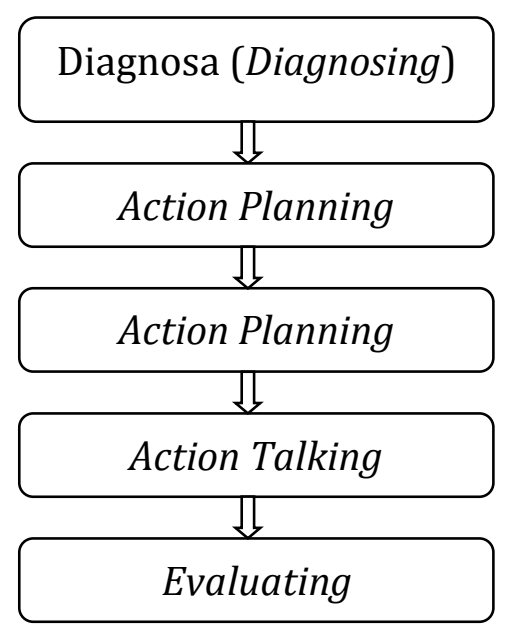

Gambar 1. Flowchart Metode Action Research

Adapun keterangan dari flowchat tersebut adalah:

1) Melakukan diagnosa (Diagnosing)

Melakukan mapping dan login ke tiap access point yang berada di Gedung Teknik Elektro Politeknik Negeri Sriwijaya dan mendeteksi seberapa besar gangguan yang menyebabkan kualitas sinyal wifi menurun.

2) Membuat rencana tindakan (Action Planning)

Mengidentifikasi masalah dari pengukuran pengujian kinerja dari wifi gedung teknik elektro yang terdiri dari bandwidth, throughput, delay dan packet loss.

3) Melakukan tindakan (Action Talking)

Melakukan pengukuran untuk pengujian sinyal dari wifi gedung teknik elektro dengan menggunakan tools seperti speedtest dan wireshark. 
4) Melakukan evaluasi (Evaluating)

Setelah dilakukan implementasi tindakan (action talking) selanjutnya mengoptimasi wifi mana saja yang kurang maksimal pada saat pertukaran data pada jaringan wireless tersebut.

5) Dari data yang telah dihasilkan mendapatkan sebuah kesimpulan dan cara mengoptimasi.

\section{HASIL DAN PEMBAHASAN}

Pengukuran dalam pengambilan data tersebut dilakukan menggunakan Speedtest dan wireshark sebagai software monitoring dalam pengukuran dan Ekhau Heatmapper. Berikut ini merupakan hasil analisa pengukuran, antara sebagai berikut:

\subsection{Analisa Sinyal Wireless}

Analisis sinyal wireless ini merupakan langkah awal sebagai penentuan level kekuatan sinyal karena kekuatan sinyal akan berpengaruh terhadap kualitas koneksi wireless. Lokasi yang dijadikan tempat penelitian ini adalah gedung kuliah teknik elektro politeknik negeri sriwijaya yang terdiri dari 3 lantai dan terdapat 5 buah access point. Pemilihan lokasi ini dikarenakan lokasi tersebut dikelilingi access point lain yang dipasang pada gedung disekelilingnya.

a. Denah lokasi pada Gedung Teknik Elektro Politeknik Negeri Sriwijaya

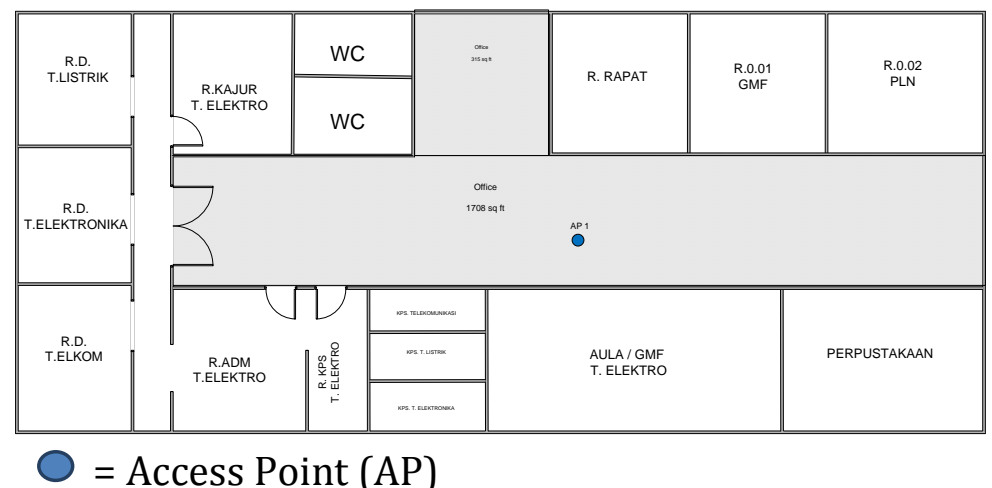

Gambar 2. Denah Lokasi Lantai Dasar

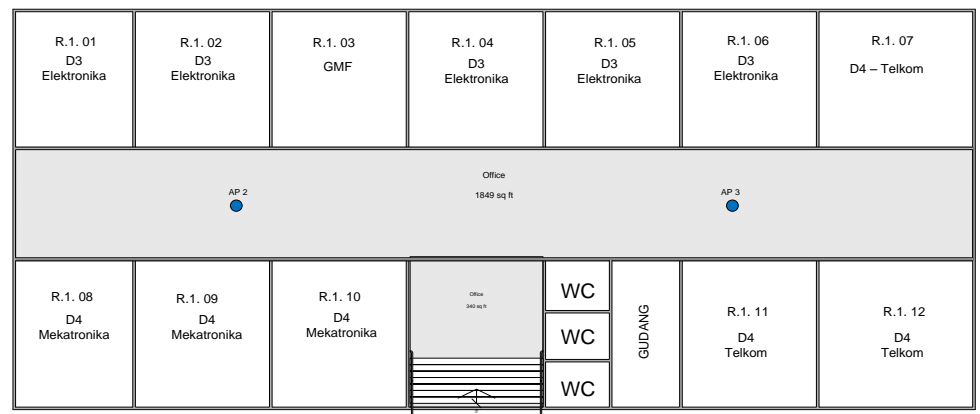


Gambar 3. Denah Lokasi Lantai 1

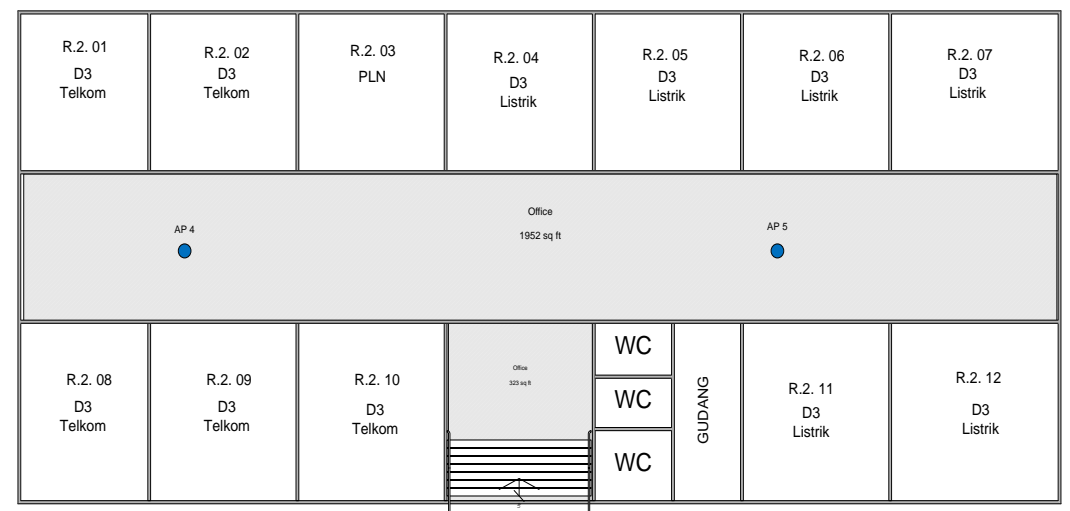

Gambar 4. Denah Lokasi Lantai 2

Untuk mengetahui kuat sinyal dari wireless tersebut menggunakan software ekahau heatmapper dengan cara mengelilingi lokasi tempat penelitian menggunakan laptop yang telah terinstal software tersebut dengan menentukan titik awal acuan terlebih dahulu.

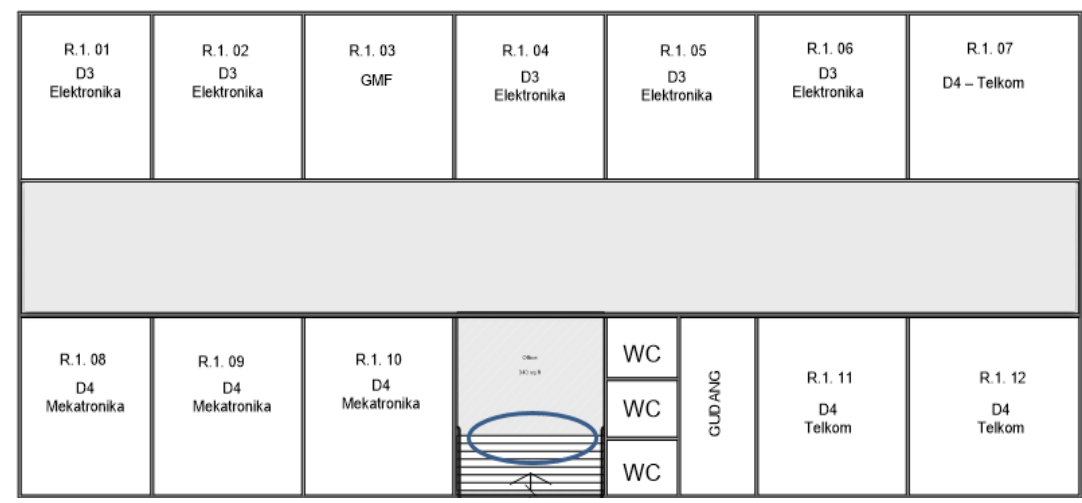

Keterangan gambar : lingkaran biru sebagai acuan awal

\subsection{Wifi}

Gambar 5. Penentuan Titik Awal

Wifi (wireless fidelity) merupakan standar jaringan internet yang ditetapkan oleh sebuah institusi internasional yang bernama IEEE (Institute of Electrical Electronic Engineers). Wifi salah satu sekumpulan standar yang digunakan WLAN (wireless local access network) untuk saling terhubung dengan internet melalui titik akses atau hotspot[2].

\subsection{Standarisasi Wireless (WLAN)}

Standarisasi wireless diatur oleh Institute of Electrical Electronic Engineers (IEEE). Standar WLAN terbagi menjadi beberapa jenis, yaitu[3]:

a. IEEE 802.11

Merupakan standar asli wireless LAN yang menetapkan tingkat perpindahan data yang paling lambat. Dikembangkan tahun 1997 
b. IEEE $802.11 \mathrm{~b}$

Menggambarkan beberapa transfer data yang paling cepat dan bersifat terbatas dalam teknologi transmisi. Dikembangkan tahun 1999

c. IEEE 802.11a

Menggambarkan pengiriman data lebih cepat dibanding IEEE 802.11b. Dikembangkan tahun 1999

d. IEEE 802.11g

Merupakan standard terbaru dari 802..11 yang menguraikan transfer data sama cepat seperti 802.11a dan 802.11b. Dikembangkan tahun 2002

Adapun perbandingan standarisasi WLAN, seperti ditunjukan pada tabel 1 di bawah ini :

Tabel 1. Perbandingan Standar 802.11[3]

\begin{tabular}{|c|c|c|c|}
\hline Spesifikasi & Kecepatan & $\begin{array}{c}\text { Frekuensi } \\
\text { Band }\end{array}$ & Client Support \\
\hline 802.11 & $2 \mathrm{Mbps}$ & $2,4 \mathrm{GHz}$ & \\
\hline $802.11 \mathrm{a}$ & $54 \mathrm{Mbps}$ & $5 \mathrm{GHz}$ & $\mathrm{A}$ \\
\hline $802.11 \mathrm{~b}$ & $11 \mathrm{Mbps}$ & $2,4 \mathrm{GHz}$ & $\mathrm{B}$ \\
\hline $802.11 \mathrm{~g}$ & $54 \mathrm{Mbps}$ & $2,4 \mathrm{GHz}$ & $\mathrm{b}, \mathrm{g}$ \\
\hline $802.11 \mathrm{n}$ & $120 \mathrm{Mbps}$ & $2,4 \mathrm{GHz}$ & b,g,n \\
\hline
\end{tabular}

\subsection{Penetapan Channel}

Terdapat 14 channel pada wireless $802.11 \mathrm{~b} / \mathrm{g} / \mathrm{n}$ yang menggunakan pita frekuensi 2,4 GHz. Jika channel saling tumpang tindih antara wireless satu dengan yang lainnya maka akan terjadi interferensi yang menyebabkan sinyal wireless tidak maksimal dan pertukaran data pada jaringan tidak optimal.

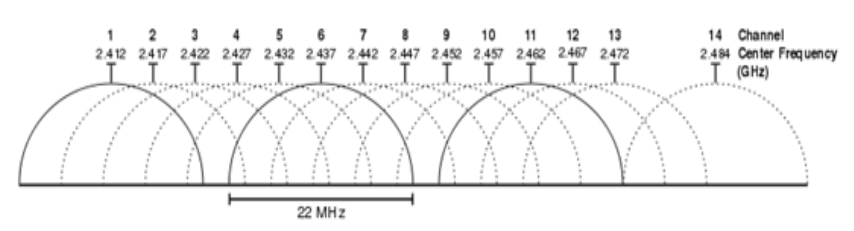

Gambar 6. Pembagian Channel 2,4 GHz

Setiap channel memiliki lebar $22 \mathrm{MHz}$, ini mengakibatkan sinyal dari sebuah channel masih dirasakan oleh channel lainnya yang bertetangga.

\subsection{Quality of Service (QoS)}

Quality of Service (QoS) merupakan salah satu teknologi yang dapat memudahkan administrator jaringan untuk menangani berbagai kendala pada suatu lalu lintas aliran paket di suatu jaringan[3]. 
Tabel di bawah ini merupakan indeks kualitas QoS (Quality of Servive)

Tabel 2. Kategori Kualitas QoS[4]

\begin{tabular}{|c|c|c|}
\hline Nilai & $\begin{array}{c}\text { Presentase } \\
(\%)\end{array}$ & Indeks \\
\hline $3,8-4$ & $95-100$ & Sangat memuaskan \\
\hline $3-3,79$ & $75-94,75$ & Memuaskan \\
\hline $2-2,99$ & $50-74,75$ & Kurang memuaskan \\
\hline $1-1,99$ & $25-49,75$ & Jelek \\
\hline
\end{tabular}

\subsection{Parameter- parameter QoS}

\section{a. Throughput}

Throughput yaitu kecepatan transfer efektif data yang diukur dalam bps (bit per second) [4]. Perhitungan throughput menggunakan rumus sebagai berikut:

Throughput $=\frac{\text { Packet data yang diterima }}{\text { Lama pengamatan }}$

Berikut merupakan tabel kategori throughput yang didapatkan berdasarkan standar TIPHON

Tabel 3. Kategori Throughput

\begin{tabular}{|c|c|c|}
\hline Kategori & Throughput & Indeks \\
\hline Sangat Bagus & $>2.1 \mathrm{Mbps}$ & 5 \\
\hline Lebih Bagus & $1.2 \mathrm{Mbps}$ s/d 2.1 Mbps & 4 \\
\hline Bagus & $700 \mathrm{Kbps} / \mathrm{d} 1.2 \mathrm{Mbps}$ & 3 \\
\hline Cukup Bagus & $338 \mathrm{~s} / \mathrm{d} 700 \mathrm{Kbps}$ & 2 \\
\hline Jelek & $0 \mathrm{~s} / \mathrm{d} 388 \mathrm{Kbps}$ & 1 \\
\hline
\end{tabular}

\section{b. Delay}

Delay merupakan waktu tunda yang dibutuhkan suatu paket yang diakibatkan oleh proses transmisi dari satu titik ke titik yang lain yang menjadi tujuannya. Delay dapat dipengaruhi oleh jarak, media fisik, kongesti atau juga waktu proses yang lama[3]. Perhitungan delay menggunakan rumus sebagai berikut :

Delay $=\frac{\text { Total Delay }}{\text { Packet packet yang diterima }}$

Delay versi Telecommunications and Internet Protocol Harmonization Over Networks (TIPHON) dikelompokkan menjadi empat kategori seperti tabel 4 di bawah ini: 
Tabel 4. Kategori Delay[3]

\begin{tabular}{|c|c|c|}
\hline Kategori & Delay & Indeks \\
\hline Sangat Bagus & $<150 \mathrm{~ms}$ & 4 \\
\hline Bagus & $150 \mathrm{~ms} \mathrm{~s} / \mathrm{d} \mathrm{300} \mathrm{ms}$ & 3 \\
\hline Sedang & $300 \mathrm{~ms} \mathrm{~s} / \mathrm{d} \mathrm{450} \mathrm{ms}$ & 2 \\
\hline Jelek & $>450 \mathrm{~ms}$ & 1 \\
\hline
\end{tabular}

\section{c. Packet Loss}

Packet loss merupakan suatu parameter yang dapat menggambarkan jumlah total packet yang hilang. Kegagalan packet dapat disebabkan karena terjadinya overload trafik dan tabrakan (congestion) dalam suatu jaringan [5]. Perhitungan packet loss dapat dicari menggunakan rumus sebagai berikut:

Packet Loss $=\frac{\text { Packet data yang dikirim }- \text { Packet data yang diterima }}{\text { Packet data yang dikirim }} \times 100 \%$

Packet loss versi Telecommunications and Internet Protocol Harmonization Over Networks (TIPHON) seperti pada tabel di bawah ini

Tabel 5. Kategori Packet Loss[4]

\begin{tabular}{|c|c|c|}
\hline Kategori & Packet Loss & Indeks \\
\hline Sangat Bagus & $0 \%$ & 4 \\
\hline Bagus & $3 \%$ & 3 \\
\hline Sedang & $15 \%$ & 2 \\
\hline Jelek & $25 \%$ & 1 \\
\hline
\end{tabular}

\subsection{Perangkat lunak (software)}

Perangkat lunak (software) sebagai pendukung dalam penelitian ini terdiri dari:

a) Speedtest

Merupakan tools untuk mengecek kecepatan internet yang digunakan.

b) Wireshark

Merupakan salah satu tools atau aplikasi open source yang digunakan sebagai alat untuk analisa protocol jaringan. Pada penelitian ini wireshark digunakan untuk mengukur besar QoS (Quality of Service).

c) Ekahau Heatmapper

Merupakan perangkat lunak open source untuk melihar cakupan jaringan wifi. Pada penelitian ini software ini juga dapat digunakan untuk melihat channel yang digunakan pada wifi.

\subsection{Kekuatan Sinyal}


Jurnal Riset Sistem Informasi Dan Teknik Informatika (JURASIK)

Volume (4) Juli 2019, pp 95-105

ISSN: 2527-5771/EISSN: 2549-7839

http://tunasbangsa.ac.id/ejurnal/index.php/jurasik

Pengumpulan data pada masing-masing access point (AP) dilakukan pada saat jam perkuliahan antara pukul 13.00 WIB-16.00 WIB

a. Hasil Pengujian kekuatan sinyal

Berikut hasil pada Ekahau Heatmapper:

AP

AP

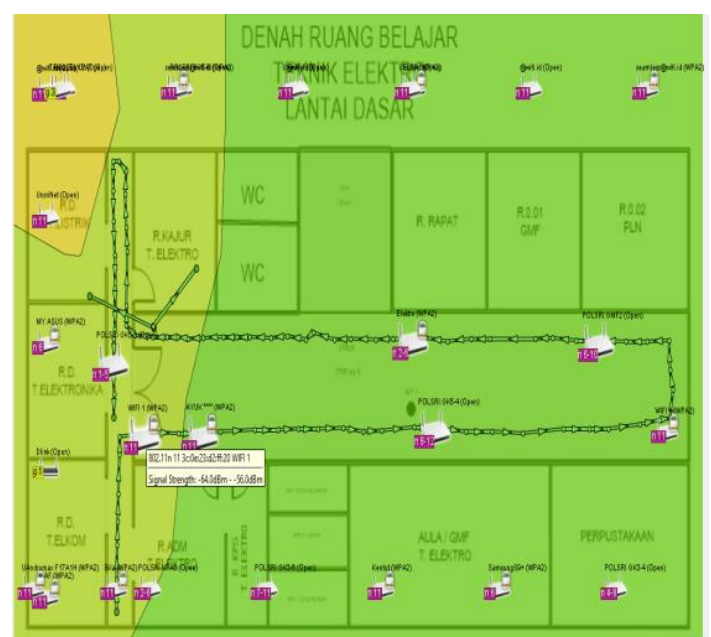

AP 2

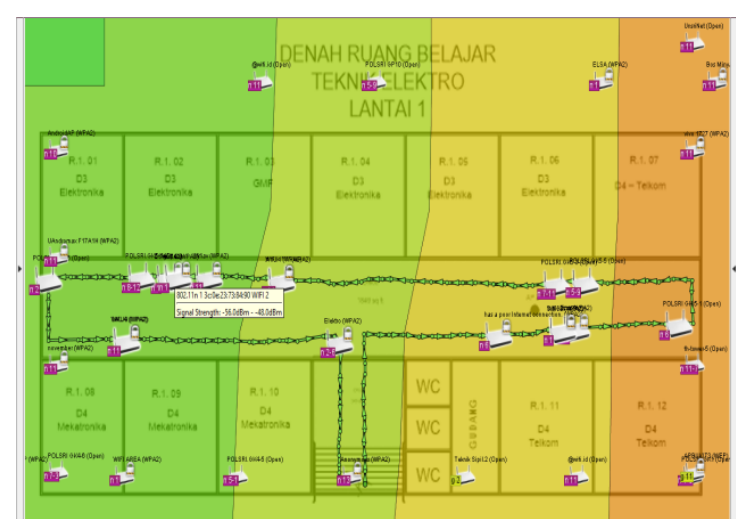

AP 3

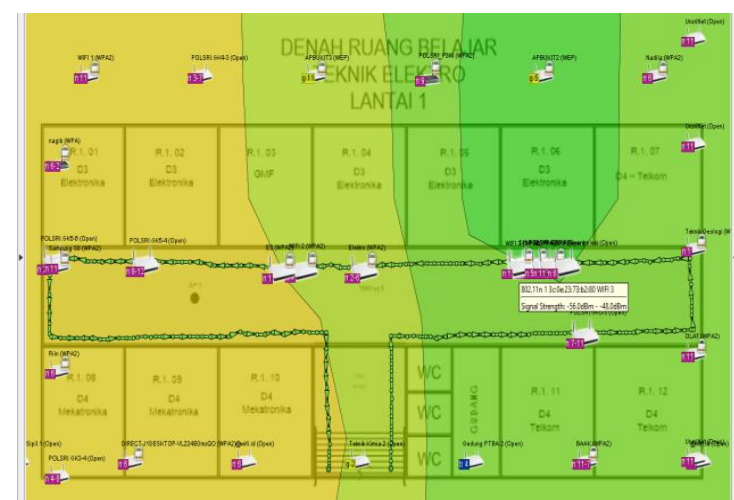

After
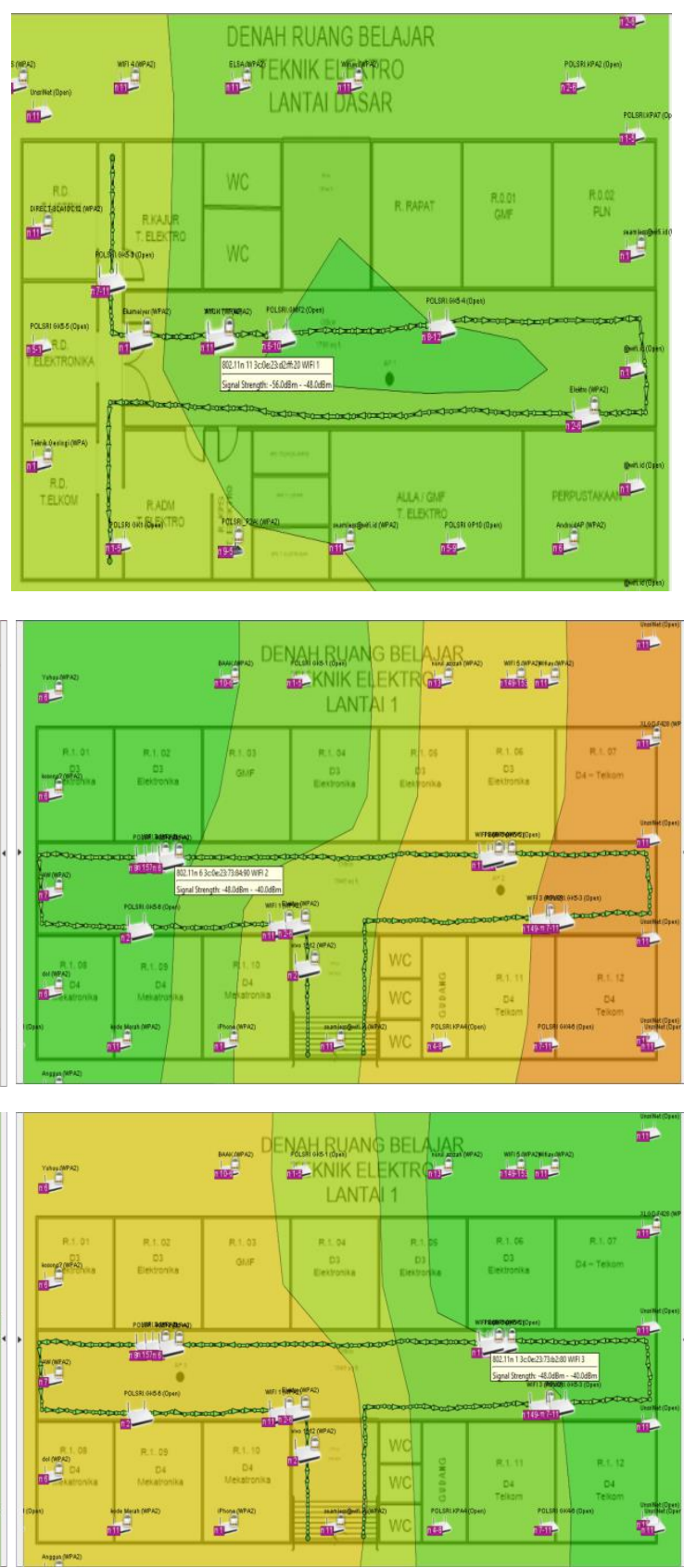

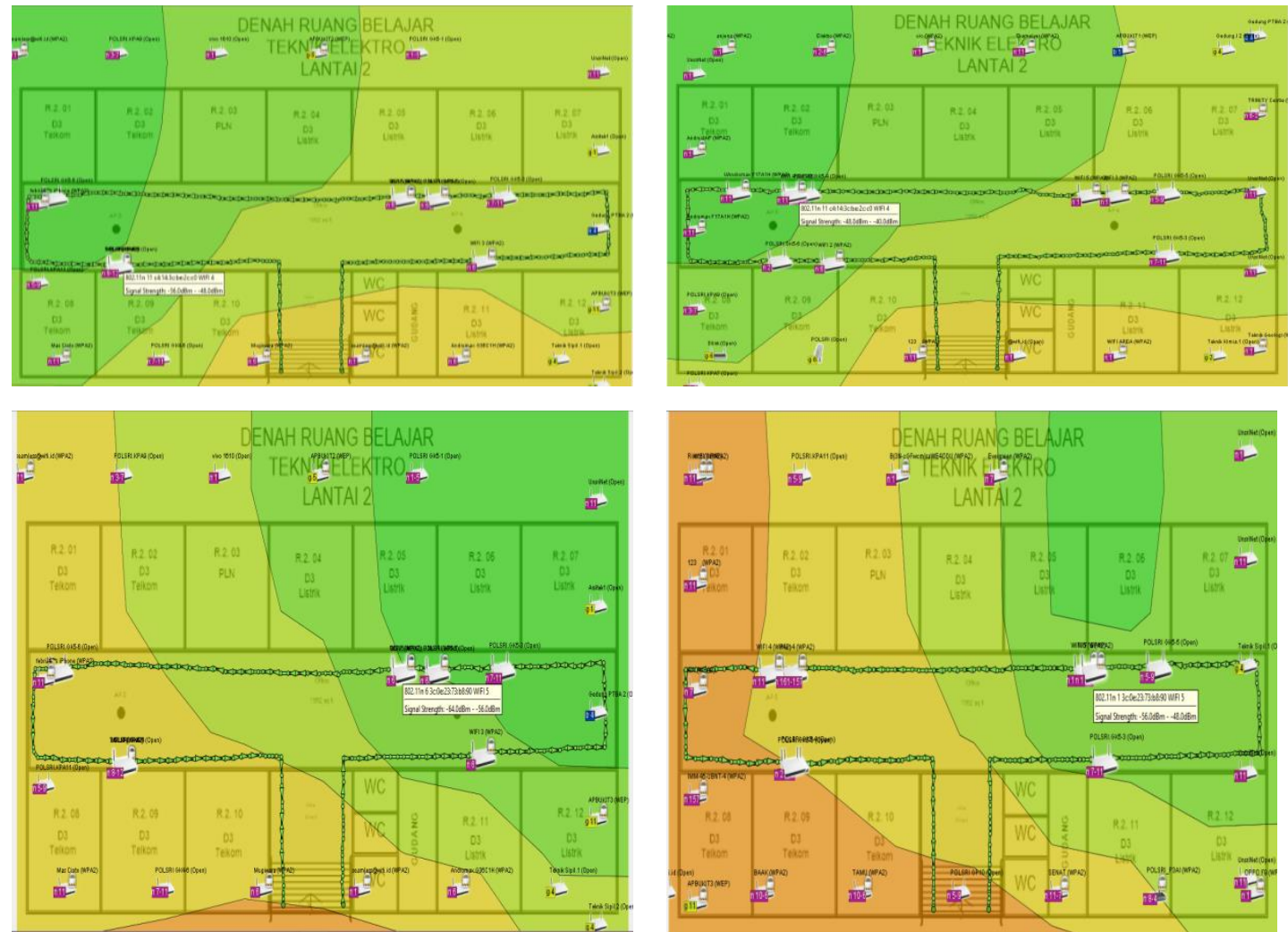

Gambar 7. Hasil pada Ekahau Heatmapper

Dari hasil diatas terlihat bahwa semua area terlayani cakupan dari wifi yang diteliti. Dapat dilihat adanya perbedaan kategori warna yang mewakili besar kuat sinyal dari wifi tersebut yang dapat dilihat pada tabel 6 dibawah ini:

Tabel 6. Kategori Kekuatan Sinyal

\begin{tabular}{|c|c|c|c|}
\hline Category & $\begin{array}{c}\text { Signal strength } \\
\text { colour }\end{array}$ & Range & Percentage \\
\hline Excellent & Green & -57 to $-10 \mathrm{dBm}$ & $75-100 \%$ \\
\hline Good & Yellow & -75 to $-58 \mathrm{dBm}$ & $40-74 \%$ \\
\hline Fair & Orange & -85 to $-76 \mathrm{dBm}$ & $20-39 \%$ \\
\hline Poor & Red & -95 to $-86 \mathrm{dBm}$ & $0-19 \%$ \\
\hline
\end{tabular}

Dari gambar 6 diatas terlihat bahwa terdapat beberapa channel yang digunakan pada masing-masing jaringan wireless di lokasi yang diteliti. Channel jaringan yang diteliti berada pada channel 1 sedangkan jaringan wireless lain berada pada channel 11 dan 6, terdapat juga jaringan wireless lain yang menggunakan channel 1 tetapi kuat sinyal tidak terlalu besar sehingga tidak menimbulkan interferensi. Jika menggunakan channel yang sama antara jaringan wireless terdekat akan terjadi interferensi yang mengakibatkan kurang optimalnya kekuatan sinyal dari wireless tersebut maka dari itu diperlukannya optimasi dengan melakukan konfigurasi channel pada access point. 
b. Hasil pengukuran kekuatan sinyal sebelum dan sesudah di optimasi

Tabel 7. Pengukuran kekuatan sinyal

\begin{tabular}{|c|c|c|c|c|}
\hline AP & Before $(\mathrm{dBm})$ & Category & After $(\mathrm{dBm})$ & Category \\
\hline AP 1 & $(-64,0)$ to $(-56,0)$ & Good & $(-56,0)$ to $(-48,0)$ & Excellent \\
\hline AP 2 & $(-56,0)$ to $(48,0)$ & Excellent & $(-48,0)$ to $(-40,0)$ & Excellent \\
\hline AP 3 & $(-56,0)$ to $(-48,0)$ & Excellent & $(-48,0)$ to $(-40,0)$ & Excellent \\
\hline AP 4 & $(-56,0)$ to $(-48,0)$ & Excellent & $(-48,0)$ to $(-40,0)$ & Excellent \\
\hline AP 5 & $(-64,0)$ to $(-56,0)$ & Good & $(-56,0)$ to $(-48,0)$ & Excellent \\
\hline
\end{tabular}

Pengukuran kuat sinyal yang didapatkan dari sofware Ekahau heatmapper terlihat bahwa hasil kekuatan sinyal dari semua access point (AP) mengalami peningkatan dan berkategori excellent. Hasil ini mempengaruhi jangkauan dari sinyal access point (AP) tersebut.

c. Hasil pengukuran bandwidth berupa upload dan download

Tabel 8. Pengukuran Bandwidth

\begin{tabular}{|c|c|c|c|c|}
\hline \multirow{2}{*}{ AP } & \multicolumn{2}{|c|}{ Before } & \multicolumn{2}{c|}{ After } \\
\cline { 2 - 5 } & Download (Mbps) & Upload (Mbps) & Download (Mbps) & Upload (Mbps) \\
\hline AP 1 & 29,1 & 29,2 & 52,9 & 54,4 \\
\hline AP 2 & 11,8 & 21,6 & 51,5 & 50,7 \\
\hline AP 3 & 17,2 & 36,5 & 51,5 & 50,9 \\
\hline AP 4 & 25,0 & 37,4 & 51,1 & 50,4 \\
\hline AP 5 & 18,3 & 47,6 & 51,8 & 50,7 \\
\hline
\end{tabular}

Hasil bandwidth tersebut didapatkan menggunakan Speedtest. Pada before, download di setiap AP dibawah 30 Mbps, upload di bawah 50 Mbps dan after mendapatkan hasil download dan upload diatas 50 Mbps pada setiap AP. Semakin besar bandwidth maka semakin besar jumlah atau kapasitas data yang bisa ditransfer dan pengiriman data lebih cepat.

d. Pengukuran ini dilakukan pada sisi client untuk mengetahui kualitas layanan wireless pada masing - masing access point (AP), dapat dilihat pada tabel 9 dibawah ini

Tabel 9. Hasil pengukuran QoS

\begin{tabular}{|c|c|c|c|}
\hline \multirow{2}{*}{ AP } & \multicolumn{3}{|c|}{ Parameter QoS } \\
\cline { 2 - 4 } & Throughput & Delay & Packet Loss \\
\hline AP 1 & $720 \mathrm{Kbps}$ & $94,08 \mathrm{~ms}$ & $0 \%$ \\
\hline AP 2 & $792 \mathrm{Kbps}$ & $146,21 \mathrm{~ms}$ & $0 \%$ \\
\hline AP 3 & $1,60 \mathrm{Mbps}$ & $182,35 \mathrm{~ms}$ & $0 \%$ \\
\hline AP 4 & $704 \mathrm{Kbps}$ & $125,83 \mathrm{~ms}$ & $0 \%$ \\
\hline AP 5 & $1,26 \mathrm{Mbps}$ & $165,02 \mathrm{~ms}$ & $0 \%$ \\
\hline
\end{tabular}


Hasil QoS yang di dapatkan yaitu throughput pada AP 1,2,4 berkategori "Bagus" dan AP 3,5 berkategori "Lebih bagus". Delay pada AP 1,2,4 berkategori "Sangat bagus", AP 3,5 berkategori "Bagus". Sedangkan packet loss semua AP berkategori "Sangat bagus".

\section{SIMPULAN}

Berdasarkan penelitian ini optimasi dilakukan dengan cara mengevaluasi pemilihan channel pada setiap access point yang diteliti dengan access point yang disekitar, hasil yang di dapatkan dari 3 pengukuran pada kekuatan sinyal, bandwidth,dan QoS (Quality of Service) yaitu, yang pertama hasil pengukuran kekuatan sinyal yang di dapatkan menggunakan software Ekahau heatmapper yang di dapatkan bahwa semua access point (AP) berkategori excellent dan mengalami peningkatan seperti pada AP 1 sebelum di optimasi $(-64,0) \mathrm{dBm}$ to ($56,0) \mathrm{dBm}$ berkategori good dan sesudah di optimasi $(-56,0) \mathrm{dBm}$ to $(-48,0) \mathrm{dBm}$ berkategori excellent. Pengukuran kedua yaitu bandwidth yang didapatkan menggunakan speedtest juga mengalami peningkatan pada upload dan download pada semua access point (AP). Pengukuran ketiga yaitu QoS (Quality of Service), hasil yang di dapatkan menggunakan software wireshark bahwa semua parameter-parameter dari QoS apabila dibandingkan berdasarkan standarisasi TIPHON masuk ke dalam kategori memuaskan. Setelah dilakukan optimasi maka kualitas layanan jaringan internet di gedung Teknik Elektro Politeknik Negeri Sriwijaya lebih maksimal.

\section{DAFTAR PUSTAKA}

[1] Y. Yanti and N. Pramita, "ANALISA PENGUKURAN INTERFERENSI PADA ACCES POINT ( AP ) UNTUK MENGETAHUI KUALITAS QUALITY OF SERVICE ( QoS ),” J. Nas. Komputasi dan Teknol. Inf., vol. 1, no. 1, pp. 17-21, 2018.

[2] H. Nugroho and S. A. Siagian, "Analisis Bandwidth Jaringan Wifi," ICT Penelit. dan Penerapan Teknol., vol. 4, no. 6, pp. 35-43, 2013.

[3] H. Nugroho and S. A. Siagian, "Analisis Bandwidth Jaringan Wifi," ICT Penelit. dan Penerapan Teknol., vol. 4, no. 6, pp. 35-43, 2013.

[4] Iskandar and A. Hidayat, "Analisa Quality of Service (QoS) Jaringan Internet Kampus (Studi Kasus: UIN Suska Riau),” J. CoreIT, vol. 1, no. 2, pp. 2460-738, 2015.

[5] R. Wulandari, "ANALISIS QoS (QUALITY OF SERVICE) PADA JARINGAN INTERNET (STUDI KASUS : UPT LOKA UJI TEKNIK PENAMBANGAN JAMPANG KULON - LIPI),” J. Tek. Inform. dan Sist. Inf., vol. 2, no. 2, pp. 162-172, 2018. 